\title{
Article \\ Deletion of the Imprinted Phlda2 Gene Increases Placental Passive Permeability in the Mouse
}

\author{
Emily Angiolini ${ }^{1,2,3, \dagger}$, Ionel Sandovici ${ }^{1,2,4} \mathbb{D}$, Philip M. Coan ${ }^{4} \ddagger\left(\mathbb{D}\right.$, Graham J. Burton ${ }^{4} \mathbb{D}$, Colin P. Sibley ${ }^{5,6} \mathbb{D}$, \\ Abigail L. Fowden ${ }^{4,7}$ and Miguel Constância $1,2,4, * \mathbb{D}$
}

1 University of Cambridge Metabolic Research Laboratories and MRC Metabolic Diseases Unit, Institute of Metabolic Science, Addenbrookes Hospital, Cambridge CB2 0QQ, UK; emily.angiolini@earlham.ac.uk (E.A.); is299@cam.ac.uk (I.S.)

2 Department of Obstetrics and Gynaecology, National Institute for Health Research Cambridge Biomedical Research Centre, Cambridge CB2 0SW, UK

3 Epigenetics Programme, The Babraham Institute, Babraham Research Campus, Cambridge CB22 3AT, UK

4 Centre for Trophoblast Research, Department of Physiology, Development and Neuroscience, University of Cambridge, Cambridge CB2 3EG, UK; p.m.coan.02@cantab.net (P.M.C.); gjb2@cam.ac.uk (G.J.B.); alf1000@cam.ac.uk (A.L.F.)

5 Maternal and Fetal Health Research Centre, Division of Developmental Biology and Medicine, School of Medical Sciences, Faculty of Biology, Medicine and Health, The University of Manchester, Manchester M13 9WL, UK; colin.sibley@manchester.ac.uk

6 Manchester Academic Health Science Centre, St. Mary's Hospital, Manchester University NHS Foundation Trust, Manchester M13 9WL, UK

7 Department of Physiology, Development and Neuroscience, University of Cambridge, Cambridge CB2 3EG, UK

* Correspondence: jmasmc2@cam.ac.uk; Tel.: +44-1223-336873

check for

updates

Citation: Angiolini, E.; Sandovici, I.; Coan, P.M.; Burton, G.J.; Sibley, C.P.;

Fowden, A.L.; Constância, M.

Deletion of the Imprinted Phlda2 Gene Increases Placental Passive Permeability in the Mouse. Genes 2021, 12, 639. https://doi.org/ 10.3390/genes12050639

Academic Editor: Fabio Coppedè

Received: 14 March 2021

Accepted: 23 April 2021

Published: 25 April 2021

Publisher's Note: MDPI stays neutral with regard to jurisdictional claims in published maps and institutional affiliations.

Copyright: (C) 2021 by the authors. Licensee MDPI, Basel, Switzerland. This article is an open access article distributed under the terms and conditions of the Creative Commons Attribution (CC BY) license (https:/ / creativecommons.org/licenses/by/ $4.0 /)$.
+ Current address: Scientific Training and Education, Earlham Institute, Norwich NR4 7UZ, UK.

$\ddagger$ Current address: Freeline Therapeutics, Stevenage Bioscience Catalyst, Gunnels Wood Road, Stevenage SG1 2F, UK.

Abstract: Genomic imprinting, an epigenetic phenomenon that causes the expression of a small set of genes in a parent-of-origin-specific manner, is thought to have co-evolved with placentation. Many imprinted genes are expressed in the placenta, where they play diverse roles related to development and nutrient supply function. However, only a small number of imprinted genes have been functionally tested for a role in nutrient transfer capacity in relation to the structural characteristics of the exchange labyrinthine zone. Here, we examine the transfer capacity in a mouse model deficient for the maternally expressed Phlda2 gene, which results in placental overgrowth and a transient reduction in fetal growth. Using stereology, we show that the morphology of the labyrinthine zone in Phlda2 ${ }^{-/+}$mutants is normal at E16 and E19. In vivo placental transfer of radiolabeled solutes ${ }^{14} \mathrm{C}$-methyl-D-glucose and ${ }^{14} \mathrm{C}$-MeAIB remains unaffected at both gestational time points. However, placental passive permeability, as measured using two inert hydrophilic solutes $\left({ }^{14} \mathrm{C}\right.$-mannitol; ${ }^{14} \mathrm{C}$-inulin), is significantly higher in mutants. Importantly, this increase in passive permeability is associated with fetal catch-up growth. Our findings uncover a key role played by the imprinted Phlda2 gene in modifying placental passive permeability that may be important for determining fetal growth.

Keywords: Phlda2; genomic imprinting; placenta; fetal growth; passive permeability

\section{Introduction}

Genomic imprinting is an epigenetic phenomenon that leads to allele-specific expression depending on the parent-of-origin of the allele [1]. Genomic imprinting is thought to have evolved independently in flowering plants with endosperm and in placental mammals, both of which have specialist structures to support the development of the offspring [2]. In mammals, there is an evolutionary link between genomic imprinting and 
placentation, strongly supporting the hypothesis that imprinted genes play key roles in allocation of maternal resources via the placenta. Reinforcing the notion that imprinted genes have a special role in placental biology, a large proportion of the approximately 100 imprinted genes identified to date in mice and humans are highly expressed in the placenta [3]. Additionally, mouse models of loss-of-imprinting, leading to either reactivation of the silent allele or silencing of the active allele, have uncovered a number of placental phenotypes, ranging from abnormal growth and structure to changes in placental transfer capacity and endocrine function (reviewed by [4-6]).

Phlda2 (pleckstrin homology-like domain family A member 2, also known as Iplimprinted in placenta and liver) is a maternally expressed gene located in a cluster of imprinted genes on distal chromosome 7 in the mouse, with shared synteny to the human chromosome 11p15.5 region. During early mouse development, prior to gastrulation, Phlda2 mRNA expression is restricted to the extra-embryonic ectoderm and the ectoplacental cone [7]. In the definitive placenta (from E10.5), expression of PHLDA2 at the mRNA and protein level persists only in the labyrinthine trophoblast until mid-gestation. It then declines markedly after E14.5, except in the chorionic plate [8,9]. Phlda2 expression is also observed at high levels in the visceral yolk sac endoderm until mid-gestation. In fetal tissues, Phlda 2 mRNA levels are moderate in liver and considerably lower in kidney, lung and limb [8]. In human placentae, PHLDA2 protein is highly expressed in the villous cytotrophoblast [10]. By contrast, low levels are present in the cytotrophoblast cells columns of anchoring villi during early pregnancy and in the extravillous trophoblast derived from them $[9,10]$. PHLDA2 protein consists of a single pleckstrin homology $(\mathrm{PH})$ domain with short N- and C-terminal extensions, which demonstrates binding to phosphatidylinositol phosphate (PIP) in vitro and is therefore likely involved in intracellular trafficking or signaling [11]. By homology to mouse PHLDA1/TDAG51, PHLDA2 may play a role in FAS-mediated apoptosis, which is consistent with a potential growth-inhibitory effect [12].

In mice, maternal deletion of the Phlda2 gene (Phlda2 ${ }^{-/+}$) leads to placentomegaly, with expansion of the junctional zone, independent of the genetic background $[9,13,14]$. Additionally, Phlda2 $2^{-/+}$leads to a transient reduction in fetal weight in late gestation on the C57BL/6J genetic background $[9,14]$ and to a global fetal growth restriction on the 129S2/SvHsd genetic background affecting both the wild-type and the mutant fetuses [13]. Within the junctional zone, Phlda2 $2^{-/+}$mutants have more glycogen stored and the expression of several placental hormone genes is increased [13]. Increased Phlda2 expression, achieved by loss-of-imprinting or insertion of a single-copy transgene, results in placental growth restriction, with loss of the spongiotrophoblast lineage and reduced placental glycogen accumulation [14,15]. Additionally, elevated Phlda2 expression leads to asymmetric fetal growth restriction $[15,16]$. In humans, the expression levels of PHLDA2 are negatively correlated with birthweight [17], and are elevated in cases of fetal growth restriction (FGR) [18-20]. Furthermore, maternal inheritance of a $15 \mathrm{bp}$ variant at the PHLDA2 promoter region that reduces its activity leads to increased birth weight [21], further demonstrating the importance of the finely balanced expression of this imprinted gene.

The overall aim of this study was to investigate the contribution of the placenta to the transitory reduction in fetal growth observed in Phlda2 $2^{-/+}$mutants [9]. To achieve this goal, we characterized the morphological and transfer properties of Phlda2 $2^{-/+}$placentae at two stages of late gestation (E16 and E19). Specifically, we used stereological techniques to establish the effects of Phlda2 $2^{-/+}$mutation on placental labyrinthine zone morphology and to estimate placental diffusion capacity, as well as placental transfer assays to determine placental transfer capacity related to passive permeability to hydrophilic solutes, facilitated diffusion and active transport in vivo.

\section{Materials and Methods}

\subsection{Mice}

The IploxP transgenic lines were produced elsewhere [9] and maintained in a C57BL/6] background. In all experiments, the mutant alleles were transmitted by a heterozygous 
mother carrying the deleted allele on her paternal chromosome, crossed with C57BL/6J wild-type males, giving the genotypes $-/+$ (subsequently called Phlda2 ${ }^{-/+}$) and $+/+$ (subsequently called Phlda2 $2^{+/+}$). Growth kinetics studies, placental transfer assays and stereological analyses were performed in $-/+$ versus $+/+$ littermates. Mice were fed a standard chow diet and housed with a $12 \mathrm{~h}$ light/dark cycle in a temperature-controlled room $\left(22{ }^{\circ} \mathrm{C}\right)$. For timed matings, the day of detection of a vaginal plug was noted as embryonic day 1 (E1). All studies were performed at the embryonic days E16 and E19.

\subsection{Genotyping}

All genotyping was performed by PCR with DNA extracted from yolk sacks, using the Expand High Fidelity PCR system (Roche) and standard cycling conditions according to the manufacturer's recommendations. Phlda2 $2^{-/+}$offspring were identified using primers: Phlda2F: 5' -TCAAGCAATGGGTAAGGG-3' and Phlda2R: 5'-TCCATCATTAGAGACAGCCA$3^{\prime}$ to amplify a $362 \mathrm{bp}$ fragment across the deletion, with an additional forward primer (5'-GTTATTCCCTCTCCACATCC-3') used to amplify a 639 bp product from the wild-type alleles (annealing temperature is $55^{\circ} \mathrm{C}$ ).

\subsection{Placental Stereology}

Stereology was performed on placentae collected at E16 and E19 and undertaken blinded to genotype. Placentae were hemisected using a double-edged razor blade, each half weighed, and immediately fixed. The stereology analysis was performed according to the protocol described previously [22]. Briefly, half of each placenta was fixed in $4 \%$ paraformaldehyde and embedded in paraffin wax, sectioned and stained using a standard hematoxylin and eosin protocol. The corresponding placental halves were fixed for $6 \mathrm{~h}$ with $4 \%$ glutaraldehyde and embedded in resin, sectioned and stained with methylene blue. The paraffin and resin-embedded counterparts were then analyzed using the Computer Assisted Stereology Toolbox (CAST) 2.0 system from Olympus (Ballerup, Denmark). The paraffin sections allow measurements for absolute placental volumes and volumes of the three main placental zones (labyrinthine zone-Lz, junctional zone- Jz and decidua basalis-Db) using the Cavalieri principle, as well as Jz/Lz volume ratios. Resin sections allow for detailed measurements of the labyrinthine zone: volume of maternal blood spaces (MBS), fetal capillaries (FC) and labyrinthine trophoblast (LT), the surface areas of the MBS and FC and the thickness of the labyrinthine interhemal membrane (IMT), as well as calculating the theoretical diffusion capacity (TDC) and the specific diffusion capacity (SDC), as described [22]. TDC indicates the potential of the labyrinthine interhemal membrane for passive diffusion, and SDC is a measure of how effective the interhemal membrane of the placenta is at meeting fetal needs [22].

\subsection{Placental Transfer Assays of Radio-Labelled Solutes}

Placental transfer assays (PTAs) were performed in pregnant heterozygous females crossed with C57BL/6J males at E16 or E19 using the following radiolabeled tracers: ${ }^{14} \mathrm{C}$-mannitol, ${ }^{14} \mathrm{C}$-inulin-carboxyl and the non-metabolizable analogues, ${ }^{14} \mathrm{C}$-methyl-Dglucose and ${ }^{14} \mathrm{C}$-methyl-aminoisobutyric acid (MeAIB; a specific substrate of System A amino acid transporters). Details regarding PTAs have been described elsewhere [23,24]. Radioactive counts in each fetus (measured as DPM-disintegrations per minute) were used to calculate the amount of radioisotope transferred per gram of Lz or per gram of fetus. The weight of Lz was estimated by multiplying individual placental weights with an average Lz percentage value determined by placental stereology for each genotype and gestational stage (from 3 litters, as previous described for similar conversions [25]). Average values for Phlda2 $2^{+/+}$controls and Phlda2 $2^{-/+}$mutant fetuses within a litter were calculated and expressed as the Phlda2 $2^{-/+} / P h l d a 2^{+/+}$ratio for that litter. These values could be used to calculate a mean for all litters at E16 and E19. The fetal accumulation of radioisotope expressed relative to Lz weight and plotted as the Phlda2 ${ }^{-/+} / \mathrm{Phlda2}^{+/+}$ratio gives a relative measure of $\mathrm{Lz}$ transfer of the solute. The fetal accumulation of radioisotope 
expressed relative to fetal weight gives a relative measure of the amount of solute received by the fetus.

\subsection{Statistical Analysis}

No explicit power analyses were used to predetermine sample size. All normally distributed data were analyzed by means of two-way analyses of variance with "litters" and "genotype" as the two factors. Data are expressed as means \pm standard error of the mean (SE). For data representing radioactive counts, a logarithmic transformation was carried out before statistical analysis. The summary data from these experiments were then presented as ratios, together with $95 \%$ confidence limits or as DPM/g Lz or DPM/g fetus \pm SE.

\section{Results}

\subsection{Phlda2 $2^{-/+}$Mutants Show Placental Overgrowth Associated with Transitory Reduction in Fetal Growth}

Maternal inheritance of Phlda2 ${ }^{-/+}$deletion on the C57BL/6J genetic background led to placental overgrowth and a transient reduction in fetal growth as previously reported $[9,14]$. Mutant placentae were on average $~ 129 \%$ of Phlda2 ${ }^{+/+}$littermates at both E16 and E19 of gestation (Table 1) $(p<0.001)$, whereas there was a modest but significant reduction in fetal weight to $96 \%$ at E16 $(p<0.05)$, which was lost by E19 $(99 \%, p=$ NS, not significant). As a result, the Phlda2 $2^{-/+}$mutants displayed decreased fetal-to-placental $(\mathrm{F} / \mathrm{P})$ weight ratios in comparison to Phlda2 ${ }^{+/+}$control littermates (Table 1).

Table 1. Fetal weights, placental weights and F/P weight ratios for Phlda2 ${ }^{-/+}$mutants and Phlda2 ${ }^{+/+}$controls.

\begin{tabular}{|c|c|c|c|c|c|}
\hline Gestational Age & Genotype & $\mathbf{N}$ & Fetal Wet Weight $(\mathrm{g}) \pm \mathrm{SE}$ & Placental Wet Weight $(\mathrm{g}) \pm \mathrm{SE}$ & F/P Weight Ratios \pm SE \\
\hline \multirow{3}{*}{ E16 } & \multirow{3}{*}{$\begin{array}{c}\text { Phlda2 } 2^{+/+} \\
\text {Phlda2 } 2^{-/+} \\
(\% \text { of } \\
\left.\text { Phlda2 }^{+/+}\right)\end{array}$} & \multirow{3}{*}{$\begin{array}{l}48 \\
49\end{array}$} & $0.398 \pm 0.005$ & $0.100 \pm 0.002$ & $4.007 \pm 0.083$ \\
\hline & & & $0.384 \pm 0.005$ & $0.129 \pm 0.002$ & $3.099 \pm 0.081$ \\
\hline & & & $96.4^{*}$ & $129.7^{* * *}$ & $77.3^{* * *}$ \\
\hline \multirow{3}{*}{ E19 } & \multirow{3}{*}{$\begin{array}{c}\text { Phlda2 } 2^{+/+} \\
\text {Phlda2 } 2^{-/+} \\
(\% \text { of } \\
\left.\text { Phlda2 } 2^{+/+}\right)\end{array}$} & \multirow{3}{*}{$\begin{array}{l}88 \\
94\end{array}$} & $1.079 \pm 0.009$ & $0.082 \pm 0.001$ & $13.395 \pm 0.227$ \\
\hline & & & $1.069 \pm 0.009$ & $0.106 \pm 0.001$ & $10.247 \pm 0.172$ \\
\hline & & & 99.1 & $129.3^{* * *}$ & $76.5^{* * *}$ \\
\hline
\end{tabular}

F/P weight ratios $=$ Fetal wet weight $/$ Placental wet weight. ${ }^{*} p<0.05 ;{ }^{* * *} p<0.001$.

\subsection{Placental Overgrowth in Phlda2 ${ }^{-/+}$Mutants Does Not Affect the Labyrinthine Zone}

Next, we investigated whether the placental overgrowth, which was previously reported to be restricted to the endocrine zone (or junctional zone), also affected the transport zone (labyrinthine zone), by performing in-depth stereological analysis throughout the whole of the placenta. The marginal increases in Lz volume $(110 \%$ and $115 \%$ of Phlda2 ${ }^{+/+}$littermates at E16 and E19, respectively) were not statistically significant (Table 2). This finding is in contrast to the significant increases in absolute volume of the $\mathrm{Jz}$ to $222 \%$ and $155 \%$ of Phlda2 $^{+/+}$control littermates at E16 and E19, respectively $(p<0.01)$ As a result, the Jz/Lz ratio increased almost two-fold in Phlda2 $2^{-/+}$at E16 $(p<0.01)$, but was similar between the two genotypes at E19 $(129 \% ; p=$ NS) (Table 2). The latter finding is mainly due to the well-established changes in the proportions of the two zones near term (i.e., a decrease in the junctional zone and an increase in the labyrinthine zone, as described previously [22]). 
Table 2. Absolute volumes of components in the placenta of Phlda2 ${ }^{-/+}$mutants and Phlda2 ${ }^{+/+}$controls at two gestational stages (E16 and E19).

\begin{tabular}{ccccccc}
\hline & \multicolumn{3}{c}{ E16 } & & E19 \\
\cline { 2 - 7 } & Phlda2 $^{+/+}$ & Phlda2 $^{-/+}$ & $\begin{array}{c}\text { \% of } \\
\text { Phlda2 }^{+/+}\end{array}$ & Phlda2 $^{+/+}$ & Phlda2 $^{-/+}$ & Phlda $^{+/+}$ \\
\hline Placenta & $93.49 \pm 3.215$ & $139.36 \pm 5.754$ & $149^{* *}$ & $88.73 \pm 7.377$ & $116.41 \pm 1.677$ & $1311^{*}$ \\
\hline $\mathrm{Lz}$ & $40.71 \pm 2.151$ & $44.89 \pm 1.575$ & 110 & $44.13 \pm 5.668$ & $50.60 \pm 2.122$ & 115 \\
\hline $\mathrm{Jz}$ & $32.14 \pm 0.172$ & $71.31 \pm 8.042$ & $222^{* *}$ & $30.54 \pm 1.176$ & $47.26 \pm 2.597$ & $155^{* *}$ \\
\hline $\mathrm{Db}$ & $18.13 \pm 1.499$ & $19.78 \pm 4.538$ & 109 & $11.07 \pm 1.603$ & $13.82 \pm 1.535$ & 125 \\
\hline $\mathrm{Jz} / \mathrm{Lz}$ & $0.80 \pm 0.049$ & $1.58 \pm 0.138$ & $198^{* *}$ & $0.73 \pm 0.110$ & $0.94 \pm 0.081$ & 129 \\
\hline
\end{tabular}

Values are mean \pm SE volume $\left(\mathrm{mm}^{3}\right) ; \mathrm{n}=9$ per genotype at E16 and $\mathrm{n}=6$ per genotype at E19 from 3 litters/group; Lz-labyrinthine zone; Jz-junctional zone; $\mathrm{Db}$-decidua basalis; ${ }^{*} p<0.05{ }^{* *} p<0.01$.

Within the Lz, further stereological analyses were made on resin sections, namely absolute measurements of the transport epithelium: labyrinthine trophoblast (LT), maternal blood spaces (MBS) and fetal capillaries (FC). Of these three Lz components (LT, MBS and FC), only the volume of MBS was significantly increased in Phlda2 ${ }^{-/+}$placentae, specifically at E19 $(151 \% ; p<0.05)$ (Table 3). However, the surface areas occupied by MBS, LT, FC were normal, as was the interhemal membrane thickness (IMT) at both E16 and E19 (Table 3). The theoretical diffusion capacity (TDC) and the specific diffusion capacity (SDC) of the Phlda2 $2^{-/+}$placentae, which depend to a great extent on the IMT, were not altered significantly at either E16 or E19 (Table 3). Thus, the Phlda2 ${ }^{-/+}$placentae have an enlarged $\mathrm{Jz}$, while the structure and size of the Lz compartment is normal, at least at the level of resolution provided by light microscopy-based stereology.

Table 3. Absolute quantities of Lz components in Phlda2 ${ }^{-/+}$and Phlda2 ${ }^{-/+}$placentae at E16 and E19.

\begin{tabular}{|c|c|c|c|c|c|c|}
\hline & \multicolumn{3}{|c|}{ E16 } & \multicolumn{3}{|c|}{ E19 } \\
\hline & Phlda $^{+/+}$ & Phlda2 $^{-/+}$ & $\begin{array}{c}\% \text { of } \\
{\text { Phlda } 2^{+/+}}^{-/ 2}\end{array}$ & Phlda2 $2^{+/+}$ & Phlda2 $^{-I_{+}}$ & $\begin{array}{c}\% \text { of } \\
\text { Phlda } 2^{+/+}\end{array}$ \\
\hline LT & $26.07 \pm 0.139$ & $29.57 \pm 1.418$ & 113 & $28.92 \pm 5.013$ & $30.80 \pm 1.059$ & 107 \\
\hline MBS & $7.37 \pm 1.291$ & $7.86 \pm 1.156$ & 107 & $7.47 \pm 0.754$ & $11.27 \pm 0.938$ & $151 *$ \\
\hline FC & $7.27 \pm 1.384$ & $7.45 \pm 0.154$ & 103 & $7.73 \pm 1.565$ & $8.52 \pm 1.469$ & 110 \\
\hline MBS SA & $18.40 \pm 0.929$ & $16.71 \pm 2.075$ & 91 & $22.28 \pm 2.848$ & $27.57 \pm 2.182$ & 124 \\
\hline FC SA & $14.97 \pm 1.351$ & $15.78 \pm 1.281$ & 105 & $16.65 \pm 3.058$ & $19.86 \pm 3.718$ & 119 \\
\hline IMT & $4.29 \pm 0.373$ & $4.25 \pm 0.154$ & 99 & $3.99 \pm 0.185$ & $4.08 \pm 0.295$ & 102 \\
\hline TDC & $0.0069 \pm 0.0006$ & $0.0068 \pm 0.0008$ & 99 & $0.0085 \pm 0.0011$ & $0.0104 \pm 0.0019$ & 123 \\
\hline SDC & $0.0205 \pm 0.0020$ & $0.0200 \pm 0.0033$ & 98 & $0.0072 \pm 0.0007$ & $0.0092 \pm 0.0020$ & 129 \\
\hline
\end{tabular}

Values are mean $\pm \mathrm{SE} ; \mathrm{n}=9$ per genotype at E16 and $\mathrm{n}=6$ per genotype at E19 from 3 litters/group; LT-labyrinthine trophoblast $\left(\mathrm{mm}^{3}\right)$; MBS-maternal blood spaces $\left(\mathrm{mm}^{3}\right)$; FC—fetal capillaries $\left(\mathrm{mm}^{3}\right)$; MBS SA-maternal blood spaces surface area $\left(\mathrm{cm}^{2}\right)$; FC SA—fetal capillaries surface area $\left(\mathrm{cm}^{2}\right)$; IMT—interhemal membrane thickness of the labyrinthine zone $(\mu \mathrm{m})$; TDC—theoretical diffusion capacity of the interhemal membrane $\left(\mathrm{cm}^{2} \cdot \mathrm{min}^{-1} \cdot \mathrm{kPa}^{-1}\right) ; \mathrm{SDC}$ - specific diffusion capacity $\left(\mathrm{cm}^{2} \cdot \mathrm{min}^{-1} \cdot \mathrm{kPa}^{-1} \cdot \mathrm{g}^{-1}\right) ;{ }^{*} p<0.05$.

\subsection{Phlda2 $2^{-/+}$Placentae Show Increased Passive Permeability to Hydrophilic Solutes}

To investigate the exchange properties of the Phlda2 $2^{-/+}$placentae, we started by assessing the diffusional characteristics using the inert tracers ${ }^{14} \mathrm{C}$-mannitol and ${ }^{14} \mathrm{C}$-inulin, which can only cross the placenta by passive diffusion. Surprisingly, we found that the overgrown Phlda2 $2^{-/+}$placenta had a pronounced increase in its passive permeability relative to Phlda2 ${ }^{+/+}$controls, despite unaltered surface area of the Lz components and normal IMT, TDC and SDC compared to wild-types. Accordingly, the amounts of ${ }^{14} \mathrm{C}$ mannitol and ${ }^{14} \mathrm{C}$-inulin transferred per gram Lz were significantly increased to $154 \%$ 
and $156 \%$ of the Phlda2 $2^{++}$control values at E16, respectively (Figure $1 \mathrm{~A}$ and Figure S1A). Additionally, Phlda2 $2^{-/+}$placentae transferred increased amounts of the larger inert tracer ${ }^{14} \mathrm{C}$-inulin $(134 \% ; p<0.01)$, but not ${ }^{14} \mathrm{C}$-mannitol, at E19 (Figure 1A and Figure S1A). The accumulation of the two passive diffusion markers per gram of fetus was significantly increased at both E16 and E19, i.e., Phlda2 ${ }^{-/+}$fetuses received an excess of the radioactive labels for their size relative to Phlda2 $2^{+/+}$controls (Figure 1A and Figure S1A). These results strongly suggest that the Phlda2 ${ }^{-/+}$placentae are more permeable to hydrophilic solutes than Phlda2 ${ }^{+/+}$littermates at both gestational ages.

A
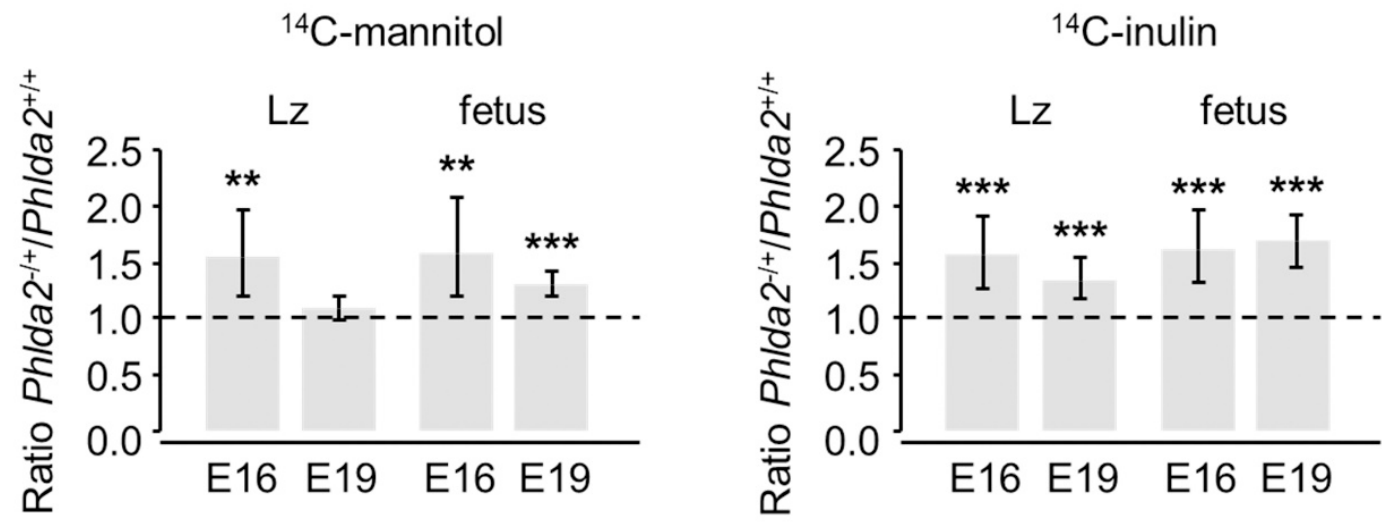

B
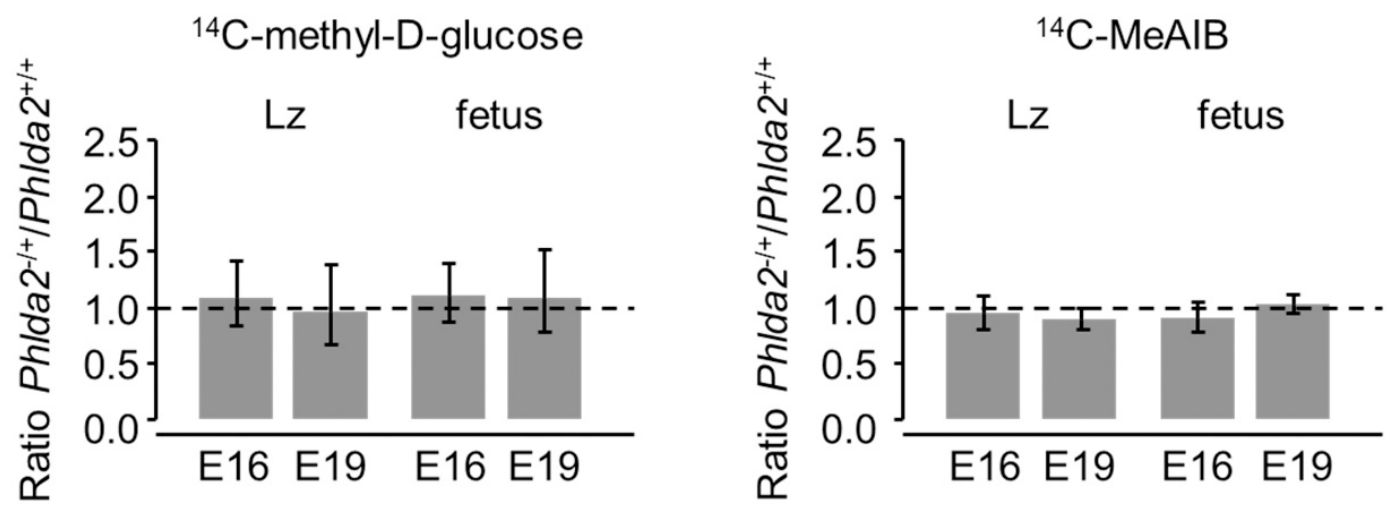

Figure 1. Placental transfer of (A) passive permeability markers $\left({ }^{14} \mathrm{C}\right.$-mannitol and ${ }^{14} \mathrm{C}$-inulin) and (B) facilitated and active transport markers $\left({ }^{14} \mathrm{C}\right.$-methyl-D-glucose and ${ }^{14} \mathrm{C}$-MeAIB, respectively) in Phlda2 ${ }^{-/+}$, calculated as a ratio of Phlda2 ${ }^{-/+}$to Phlda2 ${ }^{+/+}$transfer, expressed either per gram of labyrinthine zone (Lz) or per gram of fetus at two gestational ages (E16 and E19). Ratios $>1$ indicate increased transfer by the Phlda2 ${ }^{-/+}$mutant placenta with respect to either Lz or fetal weight (E16: ${ }^{14} \mathrm{C}$-mannitol, $\mathrm{n}=12$ Phlda2 ${ }^{+/+}$and $\mathrm{n}=15$ Phlda2 ${ }^{-/+}$from 4 litters; ${ }^{14} \mathrm{C}$-inulin, $\mathrm{n}=31$ Phlda2 $^{+/+}$and $\mathrm{n}=32$ Phlda2 $2^{/+}$ from 8 litters; ${ }^{14} \mathrm{C}$-methyl-D-glucose, $\mathrm{n}=20$ Phlda2 $^{+/+}$and $\mathrm{n}=17$ Phlda2 ${ }^{-/+}$from 6 litters; ${ }^{14} \mathrm{C}-\mathrm{MeAIB}, \mathrm{n}=16$ Phlda2 ${ }^{+/+}$ and $\mathrm{n}=17$ Phlda2 ${ }^{-/+}$from 5 litters. E19: ${ }^{14} \mathrm{C}$-mannitol, $\mathrm{n}=26$ Phlda2 $^{+/+}$and $\mathrm{n}=35$ Phlda2 ${ }^{-/+}$from 9 litters; ${ }^{14} \mathrm{C}$-inulin, $\mathrm{n}=22$ Phlda2 $2^{+/+}$and $\mathrm{n}=18$ Phlda2 ${ }^{-/+}$from 5 litters; ${ }^{14}$ C-methyl-D-glucose, $\mathrm{n}=18$ Phlda2 ${ }^{+/+}$and $\mathrm{n}=20$ Phlda2 ${ }^{-/+}$from $5 \mathrm{~L}^{14} \mathrm{C}-\mathrm{MeAIB}, \mathrm{n}=48$ Phlda2 ${ }^{+/+}$and $\mathrm{n}=42$ Phlda2 ${ }^{-/+}$from 13 litters. Bars indicate $95 \%$ confidence limits. ${ }^{* *} p<0.01$; $* * * p<0.001$.

Next, we investigated if other major transport processes, i.e., active transport and facilitated diffusion, were also affected in the Phlda2 $2^{-/+}$mutants, by assessing the in vivo flux of representative tracers, ${ }^{14} \mathrm{C}$-MeAIB and ${ }^{14} \mathrm{C}$-methyl-D-glucose, respectively. We found that the transfer of ${ }^{14} \mathrm{C}$-methyl-D-glucose per gram of Lz was similar between Phlda2 ${ }^{-/+}$ and Phlda2 ${ }^{+/+}$at both E16 and E19 (Figure 1B and Figure S1B). Accumulation of ${ }^{14} \mathrm{C}$-methyl- 
D-glucose per gram of fetus was also similar between the two genotypes at both gestational ages, i.e., mutant fetuses received an appropriate amount of ${ }^{14} \mathrm{C}$-methyl-D-glucose for their size (Figure 1B and Figure S1B). Additionally, ${ }^{14} \mathrm{C}-\mathrm{MeAIB}$ transfer per gram of Lz placenta and ${ }^{14} \mathrm{C}$-MeAIB accumulation per gram of fetus were normal at both E16 and E19 (Figure $1 \mathrm{~B}$ and Figure S1B).

We conclude that maternal transmission of the Phlda2 $2^{-/+}$deletion leads to placentae that are more permeable to hydrophilic solutes, leading to altered diffusional flux of such solutes to and from the growing fetus. This alteration seems specific to passive permeability, as transplacental flux by facilitated diffusion and active transport is normal at both E16 and E19.

\section{Discussion}

Maternal-fetal exchange by passive diffusion is responsible for a significant proportion of the total solute flux across the hemochorial placenta and is therefore thought to be a significant determinant of fetal growth $[26,27]$. Indeed, passive diffusion is responsible for the transfer of water, ions, minerals and water-soluble vitamins needed for enzyme activities [26]. This study uncovered a novel role for the imprinted Phlda2 gene as a putative negative regulator of the diffusional permeability characteristics of the mouse placenta. Our findings are based on measurements of the maternal-fetal transfer of two inert hydrophilic molecules of increasing size $\left(\mathrm{D}_{\mathrm{w}}\right.$ values of $9.9 \mathrm{~cm}^{2} / \mathrm{s} \times 10^{6}$ and $2.6 \mathrm{~cm}^{2} / \mathrm{s} \times 10^{6}$ for ${ }^{14} \mathrm{C}$ mannitol and ${ }^{14} \mathrm{C}$-inulin, respectively, see [23]) in Phlda2-deficient mice, which showed significantly enhanced transfer during late gestation. Our study adds Phlda2 to the growing list of imprinted genes with roles in the developmental regulation of diffusional exchange characteristics of the placenta. To our knowledge, this study is the first to report the action of an imprinted gene in determining maternal-fetal exchange of solutes solely by effects on passive diffusion.

In this study, we set out to explore aspects related to the placental phenotype of the Phlda2 $2^{-/+}$mouse model. First, the expression of Phlda2 is observed primarily in the trophoblast cells within the Lz, but the placental phenotypes, including placental overgrowth, were previously reported to be restricted to the Phlda2-non-expressing Jz. One of the objectives of our study was, therefore, to investigate if the lack of normal Phlda2 expression in the Lz had any functional impact in this layer, by performing in-depth stereological analyses focused on the morphological characteristics of the Lz that determine transfer capacity. Second, Phlda $2^{-/+}$mutation results in a modest and transitory reduction in fetal growth. We wanted to establish if, and how, the placenta contributes to the fetal growth phenotype, primarily by analyzing the trans-placental flux of nutrients and other solutes.

Consistent with previous findings in C57BL/6J genetic background [9], we found that Phlda2 $-/+$ conceptuses show overgrowth of the placenta by $\sim 30 \%$ at both E16 and E19. In our study, however, fetuses were approximately $4 \%$ lighter at E16 and of normal weight by E19, whereas Frank et al. reported a higher degree of FGR, with fetuses 13\% lighter at E17, with no data available at E19 or birth [9]. Based on our study alone, these observations suggest that mutant Phlda2 $2^{-/+}$fetuses undergo an initial phase of fetal growth retardation, followed by intra-uterine catch-up growth. Interestingly, on the 129S2/SvHsd genetic background, Phlda2 $2^{-/+}$fetuses did not show any weight difference compared to their Phlda2 $2^{+/+}$littermate controls at E14.5, E16.5 and E18.5 [13]. Additionally, placental overgrowth in Phlda2 $2^{-/+}$mutants was more pronounced on the 129S2/SvHsd genetic background compared to the C57BL/6J genetic background, with a maximal increase of $50 \%$ at E16.5 [13]. However, it was also observed that at E18.5 both Phlda2 $2^{++}$ and Phlda2 $2^{-/+}$fetuses were about $15 \%$ lighter when compared to wild-type litters on the 129S2/SvHsd genetic background, demonstrating that Phlda2 $2^{-/+}$mutation is affecting the phenotype in wild-type conceptuses of the same litter [13]. However, in our study, Phlda2 $2^{+/+}$fetuses from mixed litters were of similar weight to those from wild-type litters on the C57BL/6J genetic background collected subsequently, at both E16 (0.398 \pm 0.005 $(\mathrm{n}=48)$ versus $0.396 \pm 0.003(\mathrm{n}=70), p=0.91)$ and $\mathrm{E} 19(1.079 \pm 0.009(\mathrm{n}=88)$ versus 
$1.108 \pm 0.011(\mathrm{n}=37), p=0.15)$. Our stereological analyses of the placental phenotype confirmed that deletion of maternal Phlda2 allele leads to a disproportionate overgrowth of placental Jz $[9,13]$. However, we also provide evidence that the structure of Lz was remarkably normal, with the notable exception of maternal blood spaces that occupy a larger volume at E19 in mutants. The finding that the structure of Lz was largely normal was surprising, given that PHLDA2 expression is restricted to type III (fetal facing) and type II (proliferating) trophoblast cells of Lz [9]. These findings taken together are consistent with the suggestion that the overgrowth of $\mathrm{Jz}$ is controlled by signaling events taking place in Lz by unknown mechanisms [9]. An alternative explanation is that Phlda2 limits the expansion of progenitors contributing to the Jz, as previously proposed [15].

As described in detail elsewhere $[23,28]$, the rate of transfer across the placenta of an inert uncharged solute is described by Fick's Law of diffusion and gives a measure of the passive permeability. Thus, flux is determined directly by the surface area for exchange and the maternal-fetal concentration gradient, and inversely by the thickness of the barrier and the size of the molecule (usually determined by its diffusion coefficient in water at $37^{\circ} \mathrm{C}$ ). Under the conditions of our experiments, where transfer was measured as a unidirectional flux, the only variables expected to alter the transfer of the ${ }^{14} \mathrm{C}$-mannitol and ${ }^{14} \mathrm{C}$-inulin would be the surface area available for exchange and/or the thickness of the exchange barrier. Surprisingly, therefore, we measured an increase in the diffusional permeability of these solutes in the absence of any change in the stereologically measured area or thickness of the IMT, as well as TDC and SDC. However, the previously reported dependence of diffusional transfer on the size of such hydrophilic solutes [23,27], which cannot easily cross the hydrophobic plasma membrane, suggests that there must be an extracellular waterfilled route across the syncytiotrophoblast through which diffusion takes place. The nature of this extracellular water-filled route is uncertain and its dimensions would likely differ from that of the stereologically measured barrier surface area and thickness. In humans, transtrophoblastic channels [29] and syncytial denudations [30] have been suggested as providing such a route, but there is no study, of which we are aware, which addresses this issue in the mouse. We speculate that the increase in ${ }^{14} \mathrm{C}$-mannitol and ${ }^{14} \mathrm{C}$-inulin diffusion observed here in the Phlda2 $2^{-/+}$mutant, in the absence of a change in total Lz surface area or thickness, is related to a change in the length or radius of such putative routes in the trophoblast layers. We further speculate that ${ }^{14} \mathrm{C}$-inulin transfer remaining higher in the mutant at E19, whereas that of ${ }^{14} \mathrm{C}$-mannitol is normal at this gestation, is related to the number of a population of narrower channels, through which most of the diffusion of the smaller ${ }^{14} \mathrm{C}$-mannitol molecule takes place, increasing at E16 and returning to normal at E19, whereas the number of a population of wider channels, through which most of the ${ }^{14} \mathrm{C}$-inulin diffusion takes place, is increased at E16 and remains so at E19. Heterogenous channel populations in the hemochorial placenta have previously been suggested [31]. As discussed in [28], the nature of the diffusional route for hydrophilic solutes across the placenta is a fundamental piece of information lacking in our understanding of placental exchange physiology; the Phlda2 $2^{-/+}$mutant might provide a useful tool for dissecting the nature and regulation of this route.

It is tempting to speculate that the increased passive permeability of $\mathrm{Phlda}^{-/+}$placentae contributes to the intra-uterine catch-up fetal growth that is observed prior to E19. Although placental weight reaches a plateau after E16, or even decreases slightly, placental $\mathrm{Lz}$, including the interchange surface area, continues to expand until term [22]. Placental passive permeability also increases in absolute terms between E16 and E19 (Figure S1 and [23]). Phlda $2^{-/+}$fetuses received an excess of the radioactive labels for their size relative to Phlda2 ${ }^{+/+}$controls, strongly suggesting that there is increased flux of nutrients reaching the fetus. Overall, according to Fick's Law, the effect of an increased passive permeability on the transfer of individual solutes will be dependent on maternal/fetal electrochemical gradients, about which we know little in the mouse. However, to illustrate the point, if we assume the maternal plasma glucose concentration is higher than in fetal plasma, as it is in most species, then increased permeability will increase glucose flux to the fetus, in addition 
to that transferred by facilitated diffusion. However, for amino acids where the concentration gradient is usually higher in the fetal plasma than in the maternal plasma (due to active transport), then increased permeability could actually decrease net amino acid flux to the fetus, due to increased diffusional back flux in the fetal to maternal direction.

Our study is inconclusive regarding the contribution of the placenta to the reduced fetal weight observed at E16 in our study and at E17 in [9]. From our stereological studies and placental transfer studies, we conclude that the transitory reduction in fetal growth is not caused by reduced transport capacity to the fetus. However, we cannot rule out other explanations such as increased partitioning of maternal resources to the placenta to sustain the expansion of the Jz layer, as previously proposed [13]. Indeed, the placenta itself consumes approximately $35-40 \%$ of the oxygen and glucose removed from the maternal uterine circulation by the feto-placental unit [32-34]. Placental metabolism determines the types and quantities of nutrients transferred to the fetus [35]. Placental metabolism depends on the size of placenta and responds to a number of environmental cues, including diet, hormones and oxygen [36-40]. An increase in placental size overall would put a greater strain on the maternal nutrient resources, which is limited and known as maternal constraint [41,42]. Several tissues, especially the liver and kidney, express significant levels of Phlda 2 mRNA [8]. In part, the changes in fetal growth may also relate to altered Phlda2 expression in the fetal tissues, so conditional deletions of fetal and placental Phlada2 would be needed to differentiate between fetal and placental contribution to the changes in the fetal growth trajectory. These could be achieved using, for example, the Cyp19-Cre line that is active in the early diploid trophoblast cells from which both placental Lz and Jz derive [43].

We have previously shown that the developmental regulation of diffusional exchange characteristics of the placenta is an important mechanism by which imprinted genes influence placental nutrient supply and fetal growth (summarized in Table 4). Deletion in the mouse of the paternally expressed placental-specific Igf2 P0 transcript $\left(\operatorname{Ig} f 2 \mathrm{PO}^{+/-}\right)$[44] led to a small-sized placenta and reduced placental passive permeability for three inert hydrophilic solutes of increasing sizes $\left({ }^{14} \mathrm{C}\right.$-mannitol, ${ }^{51} \mathrm{CrEDTA}$, and ${ }^{14} \mathrm{C}$-inulin) at E19 of gestation, which was associated with an increase in thickness of the exchange barrier compared to littermate controls [23] (Table 4). When all Igf2 transcripts were deleted throughout the conceptus $\left(\operatorname{Ig} f 2 \mathrm{null}^{+/-}\right)$, the increase in the thickness of the barrier was milder compared to Igf2 $\mathrm{P0}^{+/-}$mutants [45] and only the permeability for the largest tracer $\left({ }^{14} \mathrm{C}\right.$-inulin) was significantly reduced at E19 of gestation [45] (Table 4). Interestingly, in both $\operatorname{Igf} 2$ models ( $I g f 2 \mathrm{P0}^{+/-}$and $\operatorname{Ig} f 2 \mathrm{null}^{+/-}$) we observed alterations in the transplacental flux of ${ }^{14} \mathrm{C}$-methyl-D-glucose and/ or ${ }^{14} \mathrm{C}$-MeAIB, as well as placental expression of amino acid and glucose transporters [24]. These findings strongly suggest that the small mutant $\operatorname{Ig} f 2 \mathrm{PO}^{+/-}$and $\mathrm{Ig} f 2 \mathrm{null}^{+/-}$placentae are capable of functional compensatory adaptations in response to either increased or decreased fetal demands for growth, respectively [24]. Overexpression of $I g f 2$, achieved through a $13 \mathrm{~kb}$ deletion that included the $H 19$ gene and the $H 19$ / Igf2-imprinting control region ICR1 $\left(H 19^{\Delta 13}\right)$, led to an enlarged placenta, with pronounced reductions in placental nutrient transfer by the three mechanisms, including passive permeability, with the amounts of ${ }^{14} \mathrm{C}$-mannitol and ${ }^{14} \mathrm{C}$-inulin transferred by the placenta significantly reduced in mutants at both E16 and E19 [42] (Table 4). In this model of Igf2 overexpression, the thickness of the exchange barrier in mutants was not different from control littermates. $R t l 1$ (retrotransposon-like 1) is a paternally expressed gene that has a demonstrated role in altering placental passive permeability [46]. Accordingly, paternal deletion of $R t l 1$ led to a significant reduction in placental passive permeability for ${ }^{14} \mathrm{C}$-inulin at E16, likely explained by areas of placental infarction observed in these mutants [46]. Altogether, these findings show that imprinted genes modify placental passive permeability, through several possible mechanisms, from regulation of the thickness of exchange barrier (Igf2P0) and altered number or size of pores (H19/Igf2, and Phlda2 as first demonstrated here), to developmental defects (Rtl1). To our knowledge, Phlda2 is the only imprinted gene described so far with a role in modulating maternal-fetal exchange of solutes solely 
by effects on passive permeability. We propose that an important novel function for this maternally expressed gene is to limit the allocation of maternal resources to the growing fetus by reducing the permeability characteristics of the placenta. This 'strategy' adopted by Phlda2 is consistent with the general roles played by maternally expressed genes in the offspring as proposed by the two most widely accepted evolutionary theories of imprinting, i.e., the kinship and maternal-offspring coadaptation.

Table 4. Effects of deletion of selected imprinted genes on placental transport characteristics at E19 of mouse pregnancy relative to their wild-type littermate controls.

\begin{tabular}{|c|c|c|c|c|c|c|c|c|}
\hline \multirow{2}{*}{ Gene Deletion } & \multirow{2}{*}{$\begin{array}{l}\text { Theoretical } \\
\text { Diffusion } \\
\text { Capacity }\end{array}$} & \multirow{2}{*}{$\begin{array}{l}\text { Passive Per- } \\
\text { meability }\end{array}$} & \multicolumn{2}{|c|}{$\begin{array}{c}\text { Transporter Mediated } \\
\text { Transport }\end{array}$} & \multicolumn{2}{|c|}{ Placental Size } & \multirow{2}{*}{$\begin{array}{l}\text { Normal Role of Gene on } \\
\text { Passive Permeability }\end{array}$} & \multirow[t]{2}{*}{ Reference } \\
\hline & & & MeAIB & Glucose & $\mathrm{Lz}$ & $\mathrm{Jz}$ & & \\
\hline Phlda2 & No $\Delta$ & $\uparrow$ (inulin) & No $\Delta$ & No $\Delta$ & No $\Delta$ & $\uparrow$ & $\begin{array}{l}\text { Restricts paracellular pore } \\
\text { length, radius or number }\end{array}$ & This study \\
\hline $\operatorname{Ig} f 2 \mathrm{P} 0$ & $\downarrow$ & $\begin{array}{l}\downarrow \text { (inulin, } \\
\text { EDTA, } \\
\text { mannitol) }\end{array}$ & No $\Delta$ & $\uparrow$ & $\downarrow$ & $\downarrow$ & $\begin{array}{c}\text { Increases TDC by reducing } \\
\text { interhemal membrane } \\
\text { thickness and increasing } \\
\text { surface area }\end{array}$ & {$[23,24]$} \\
\hline Igf2 & $\downarrow$ & $\downarrow$ (inulin) & $\downarrow$ & No $\Delta$ & $\downarrow$ & $\downarrow$ & $\begin{array}{c}\text { Increases TDC by reducing } \\
\text { interhemal membrane } \\
\text { thickness and increasing } \\
\text { surface area }\end{array}$ & {$[24,45]$} \\
\hline $\begin{array}{l}H 19^{\Delta 13} \text { (leading } \\
\quad \text { to Igf2 LOI) }\end{array}$ & $\uparrow$ & $\begin{array}{l}\downarrow \text { (inulin, } \\
\text { mannitol) }\end{array}$ & $\downarrow$ & $\downarrow$ & $\uparrow$ & $\uparrow$ & $\begin{array}{l}\text { Increases paracellular pore } \\
\text { characteristics and reduces } \\
\text { TDC through effects on } \\
\text { surface area }\end{array}$ & [42] \\
\hline
\end{tabular}

Lz-labyrinthine zone, Jz-junctional zone, No $\Delta$-no change, $\uparrow$-increase, $\downarrow$-decrease, TDC—-theoretical diffusion capacity of the interhemal membrane, LOI - Loss of Imprinting.

We also note that all imprinted genes that were assessed to date for placental passive permeability properties in transgenic studies show evidence for impaired exchange of diffusional characteristics (Rtl1, H19/Igf2, Igf2P0 and now Phlda2-see Table 4). At present, there is no evidence of interaction of imprinted genes in the regulation of passive permeability. However, it has not escaped our attention that the imprinted gene network (IGN), regulated by the zinc-finger transcription factor PLAGL1 [47], includes IC1 and IC2 genes (e.g., Igf2, H19) but also Rtl1, all of which have a major impact on placenta passive permeability. Moreover, H19 is a transregulator of the IGN, with the knock-out of H19 causing expression changes in a number of IGN genes (including Rtl1, Igf2 and Cdkn1c) [47]. It will be important to define, in future studies, how many other imprinted genes may play roles in passive diffusion and perform genetic studies targeted to the placenta to provide evidence for direct or indirect interactions between IGN genes in the regulation of passive diffusion. At the moment, we propose that Phlda2 may play a unique and specific role in the control of pore size/number, but methods to visualize and measure such pores are urgently needed.

\section{Conclusions}

Overall, in this study, we filled an important gap in our knowledge about the role played by the imprinted Phlda2 gene in the placenta. Our results reiterate the important roles played by the imprinted genes in controlling the exchange characteristics of the mouse placenta and the complex relationship between these functional properties and the detailed morphological structure of the interchange layer of placenta. By influencing placental passive permeability, Phlda2 may play an important role in fine-tuning fetal growth to reach its genetically determined potential. Further studies are needed to define the specific molecular mechanisms by which the Phlda2 gene acts on placental passive permeability. 
Supplementary Materials: The following are available online at https://www.mdpi.com/article/10 .3390 / genes12050639/s1, Figure S1: Placental transfer of passive permeability markers and facilitated and active transport markers at E16 and E19.

Author Contributions: Conceptualization, C.P.S., A.L.F., and M.C.; methodology, P.M.C., G.J.B., C.P.S., and A.L.F.; investigation, E.A., I.S., P.M.C., and M.C.; data curation and interpretation, E.A., I.S., C.P.S., A.L.F. and M.C.; writing-original draft preparation, E.A., I.S., and M.C.; writing-review and editing, I.S., G.J.B., C.P.S., A.L.F., and M.C.; visualization, E.A., and I.S.; supervision, M.C.; funding acquisition, M.C. All authors have read and agreed to the published version of the manuscript.

Funding: His work was supported by grants from the Biotechnology and Biological Sciences Research Council (BBSRC) and EU-FP6 Epigenome Network of Excellence.

Institutional Review Board Statement: All experimental procedures were conducted under licenses issued by the Home Office (UK) (PPLs 80/1467 and 80/1896) in accordance with the Animals (Scientific Procedures) Act 1986 and the Babraham Institute Animal Welfare and Ethical Review Body (AWERB).

Informed Consent Statement: Not applicable.

Data Availability Statement: Not applicable.

Acknowledgments: The authors thank the Multi-Imaging Centre of the School of Biological Sciences and Nuala Daw for their assistance in preparing the resin sections, Gerrard Peck and Oluwadamilola Iwajomo for their technical assistance during placental stereology and placental transfer assays experiments, and Eurof Walters and Anne Segonds-Pichon for help with the statistical analyses. We thank Ben Tycko for sharing the Ipl ${ }^{l o x P}$ mouse line generated in his lab, and Wolf Reik and Ben Tycko for very helpful discussions throughout this study.

Conflicts of Interest: The authors declare no conflict of interest.

\section{References}

1. Constância, M.; Kelsey, G.; Reik, W. Resourceful imprinting. Nature 2004, 432, 53-57. [CrossRef]

2. Gutierrez-Marcos, J.F.; Constância, M.; Burton, G.J. Maternal to offspring resource allocation in plants and mammals. Placenta 2012, 33 (Suppl. 2), e3-e10. [CrossRef]

3. Babak, T.; DeVeale, B.; Tsang, E.K.; Zhou, Y.; Li, X.; Smith, K.S.; Kukurba, K.R.; Zhang, R.; Li, J.B.; van der Kooy, D.; et al. Genetic conflict reflected in tissue-specific maps of genomic imprinting in human and mouse. Nat. Genet. 2015, 47, 544-549. [CrossRef]

4. Coan, P.M.; Burton, G.J.; Ferguson-Smith, A.C. Imprinted genes in the placenta-A review. Placenta 2005, 26 (Suppl. A), S10-S20. [CrossRef]

5. Angiolini, E.; Fowden, A.; Coan, P.; Sandovici, I.; Smith, P.; Dean, W.; Burton, G.; Tycko, B.; Reik, W.; Sibley, C.; et al. Regulation of placental efficiency for nutrient transport by imprinted genes. Placenta 2006, 27 (Suppl. A), S98-S102. [CrossRef]

6. John, R.M. Imprinted genes and the regulation of placental endocrine function: Pregnancy and beyond. Placenta 2017, 56, 86-90. [CrossRef] [PubMed]

7. Dunwoodie, S.L.; Beddington, R.S. The expression of the imprinted gene Ipl is restricted to extra-embryonic tissues and embryonic lateral mesoderm during early mouse development. Int. J. Dev. Biol. 2002, 46, 459-466. [PubMed]

8. Qian, N.; Frank, D.; O’Keefe, D.; Dao, D.; Zhao, L.; Yuan, L.; Wang, Q.; Keating, M.; Walsh, C.; Tycko, B. The IPL gene on chromosome 11p15.5 is imprinted in humans and mice and is similar to TDAG51, implicated in Fas expression and apoptosis. Hum. Mol. Genet. 1997, 6, 2021-2029. [CrossRef]

9. Frank, D.; Fortino, W.; Clark, L.; Musalo, R.; Wang, W.; Saxena, A.; Li, C.M.; Reik, W.; Ludwig, T.; Tycko, B. Placental overgrowth in mice lacking the imprinted gene Ipl. Proc. Natl. Acad. Sci. USA 2002, 99, 7490-7495. [CrossRef] [PubMed]

10. Saxena, A.; Frank, D.; Panichkul, P.; Van den Veyver, I.B.; Tycko, B.; Thaker, H. The product of the imprinted gene IPL marks human villous cytotrophoblast and is lost in complete hydatidiform mole. Placenta 2003, 24, 835-842. [CrossRef]

11. Saxena, A.; Morozov, P.; Frank, D.; Musalo, R.; Lemmon, M.A.; Skolnik, E.Y.; Tycko, B. Phosphoinositide binding by the pleckstrin homology domains of Ipl and Tih1. J. Biol. Chem. 2002, 277, 49935-49944. [CrossRef] [PubMed]

12. Park, C.G.; Lee, S.Y.; Kandala, G.; Lee, S.Y.; Choi, Y. A novel gene product that couples TCR signaling to Fas(CD95) expression in activation-induced cell death. Immunity 1996, 4, 583-591. [CrossRef]

13. Tunster, S.J.; Creeth, H.D.J.; John, R.M. The imprinted Phlda2 gene modulates a major endocrine compartment of the placenta to regulate placental demands for maternal resources. Dev. Biol. 2016, 409, 251-260. [CrossRef] [PubMed]

14. Salas, M.; John, R.; Saxena, A.; Barton, S.; Frank, D.; Fitzpatrick, G.; Higgins, M.J.; Tycko, B. Placental growth retardation due to loss of imprinting of Phlda2. Mech. Dev. 2004, 121, 1199-1210. [CrossRef] [PubMed]

15. Tunster, S.J.; Tycko, B.; John, R.M. The imprinted Phlda2 gene regulates extraembryonic energy stores. Mol. Cell. Biol. 2010, 30, 295-306. [CrossRef] [PubMed] 
16. Tunster, S.J.; Van De Pette, M.; John, R.M. Isolating the role of elevated Phlda2 in asymmetric late fetal growth restriction in mice. Dis. Model. Mech. 2014, 7, 1185-1191. [CrossRef]

17. Apostolidou, S.; Abu-Amero, S.; O’Donoghue, K.; Frost, J.; Olafsdottir, O.; Chavele, K.M.; Whittaker, J.C.; Loughna, P.; Stanier, P.; Moore, G.E. Elevated placental expression of the imprinted PHLDA2 gene is associated with low birth weight. J. Mol. Med. 2007, 85, 379-387. [CrossRef]

18. McMinn, J.; Wei, M.; Schupf, N.; Cusmai, J.; Johnson, E.B.; Smith, A.C.; Weksberg, R.; Thaker, H.M.; Tycko, B. Unbalanced placental expression of imprinted genes in human intrauterine growth restriction. Placenta 2006, 27, 540-549. [CrossRef]

19. Shi, X.; He, Z.; Gao, Y.; Luo, Y.; Gou, C.; Fang, Q. Placental expression of PHLDA2 in selective intrauterine growth restriction in monozygotic twins. Placenta 2014, 35, 428-430. [CrossRef]

20. Janssen, A.B.; Tunster, S.J.; Heazell, A.E.; John, R.M. Placental PHLDA2 expression is increased in cases of fetal growth restriction following reduced fetal movements. BMC Med. Genet. 2016, 17, 17. [CrossRef]

21. Ishida, M.; Monk, D.; Duncan, A.J.; Abu-Amero, S.; Chong, J.; Ring, S.M.; Pembrey, M.E.; Hindmarsh, P.C.; Whittaker, J.C.; Stanier, P.; et al. Maternal inheritance of a promoter variant in the imprinted PHLDA2 gene significantly increases birth weight. Am. J. Hum. Genet. 2012, 90, 715-719. [CrossRef]

22. Coan, P.M.; Ferguson-Smith, A.C.; Burton, G.J. Developmental dynamics of the definitive mouse placenta assessed by stereology. Biol. Reprod. 2004, 70, 1806-1813. [CrossRef] [PubMed]

23. Sibley, C.P.; Coan, P.M.; Ferguson-Smith, A.C.; Dean, W.; Hughes, J.; Smith, P.; Reik, W.; Burton, G.J.; Fowden, A.L.; Constância, M. Placental-specific insulin-like growth factor 2 ( Igf2) regulates the diffusional exchange characteristics of the mouse placenta. Proc. Natl. Acad. Sci. USA 2004, 101, 8204-8208. [CrossRef] [PubMed]

24. Constância, M.; Angiolini, E.; Sandovici, I.; Smith, P.; Smith, R.; Kelsey, G.; Dean, W.; Ferguson-Smith, A.; Sibley, C.P.; Reik, W.; et al. Adaptation of nutrient supply to fetal demand in the mouse involves interaction between the Igf2 gene and placental transporter systems. Proc. Natl. Acad. Sci. USA 2005, 102, 19219-19224. [CrossRef]

25. López-Tello, J.; Pérez-García, V.; Khaira, J.; Kusinski, L.C.; Cooper, W.N.; Andreani, A.; Grant, I.; Fernández de Liger, E.; Lam, B.Y.; Hemberger, M.; et al. Fetal and trophoblast PI3K p $110 \alpha$ have distinct roles in regulating resource supply to the growing fetus in mice. Elife 2019, 8, e45282. [CrossRef] [PubMed]

26. Bain, M.D.; Copas, D.K.; Taylor, A.; Landon, M.J.; Stacey, T.E. Permeability of the human placenta in vivo to four non-metabolized hydrophilic molecules. J. Physiol. 1990, 431, 505-513. [CrossRef]

27. Sibley, C.P. Review article: Mechanisms of ion transfer by the rat placenta: A model for the human placenta? Placenta 1994, 15, 675-691. [CrossRef]

28. Sibley, C.P.; Brownbill, P.; Glazier, J.D.; Greenwood, S.L. Knowledge needed about the exchange physiology of the placenta. Placenta 2018, 64 (Suppl. 1), S9-S15. [CrossRef]

29. Kertschanska, S.; Kosanke, G.; Kaufmann, P. Pressure dependence of so-called transtrophoblastic channels during fetal perfusion of human placental villi. Microsc. Res. Tech. 1997, 38, 52-62. [CrossRef]

30. Brownbill, P.; Mahendran, D.; Owen, D.; Swanson, P.; Thornburg, K.L.; Nelson, D.M.; Sibley, C.P. Denudations as paracellular routes for alphafetoprotein and creatinine across the human syncytiotrophoblast. Am. J. Physiol. Regul. Integr. Comp. Physiol. 2000, 278, R677-R683. [CrossRef]

31. Stulc, J. Extracellular transport pathways in the haemochorial placenta. Placenta 1989, 10, 113-119. [CrossRef]

32. Gluckman, P.D. Endocrine and nutritional regulation of prenatal growth. Acta Paediatr. Suppl. 1997, 423, 153-157. [CrossRef]

33. Carter, A.M. Placental oxygen consumption. Part I: In vivo studies-A review. Placenta 2000, 21 (Suppl. A), S31-S37. [CrossRef]

34. Vaughan, O.R.; Fowden, A.L. Placental metabolism: Substrate requirements and the response to stress. Reprod. Domest. Anim. 2016, 51 (Suppl. 2), 25-35. [CrossRef]

35. Hay, W.W., Jr. Regulation of placental metabolism by glucose supply. Reprod. Fertil. Dev. 1995, 7, 365-375. [CrossRef]

36. Coan, P.M.; Angiolini, E.; Sandovici, I.; Burton, G.J.; Constância, M.; Fowden, A.L. Adaptations in placental nutrient transfer capacity to meet fetal growth demands depend on placental size in mice. J. Physiol. 2008, 586, 4567-4576. [CrossRef]

37. Coan, P.M.; Vaughan, O.R.; McCarthy, J.; Mactier, C.; Burton, G.J.; Constância, M.; Fowden, A.L. Dietary composition programmes placental phenotype in mice. J. Physiol. 2011, 589, 3659-3670. [CrossRef]

38. Vaughan, O.R.; Sferruzzi-Perri, A.N.; Fowden, A.L. Maternal corticosterone regulates nutrient allocation to fetal growth in mice. J. Physiol. 2012, 590, 5529-5540. [CrossRef] [PubMed]

39. Nuzzo, A.M.; Camm, E.J.; Sferruzzi-Perri, A.N.; Ashmore, T.J.; Yung, H.W.; Cindrova-Davies, T.; Spiroski, A.M.; Sutherland, M.R.; Logan, A.; Austin-Williams, S.; et al. Placental Adaptation to Early-Onset Hypoxic Pregnancy and Mitochondria-Targeted Antioxidant Therapy in a Rodent Model. Am. J. Pathol. 2018, 188, 2704-2716. [CrossRef]

40. Sferruzzi-Perri, A.N.; Higgins, J.S.; Vaughan, O.R.; Murray, A.J.; Fowden, A.L. Placental mitochondria adapt developmentally and in response to hypoxia to support fetal growth. Proc. Natl. Acad. Sci. USA 2019, 116, 1621-1626. [CrossRef]

41. Gluckman, P.D.; Hanson, M.A. Maternal constraint of fetal growth and its consequences. Semin. Fetal Neonatal Med. 2004, 9 , 419-425. [CrossRef]

42. Angiolini, E.; Coan, P.M.; Sandovici, I.; Iwajomo, O.H.; Peck, G.; Burton, G.J.; Sibley, C.P.; Reik, W.; Fowden, A.L.; Constância, M. Developmental adaptations to increased fetal nutrient demand in mouse genetic models of Igf2-mediated overgrowth. FASEB J. 2011, 25, 1737-1745. [CrossRef] 
43. Wenzel, P.L.; Leone, G. Expression of Cre recombinase in early diploid trophoblast cells of the mouse placenta. Genesis 2007, 45, 129-134. [CrossRef]

44. Constância, M.; Hemberger, M.; Hughes, J.; Dean, W.; Ferguson-Smith, A.; Fundele, R.; Stewart, F.; Kelsey, G.; Fowden, A.; Sibley, C.; et al. Placental-specific IGF-II is a major modulator of placental and fetal growth. Nature 2002, 417, 945-948. [CrossRef]

45. Coan, P.M.; Fowden, A.L.; Constância, M.; Ferguson-Smith, A.C.; Burton, G.J.; Sibley, C.P. Disproportional effects of Igf2 knockout on placental morphology and diffusional exchange characteristics in the mouse. J. Physiol. 2008, 586, 5023-5032. [CrossRef] [PubMed]

46. Sekita, Y.; Wagatsuma, H.; Nakamura, K.; Ono, R.; Kagami, M.; Wakisaka, N.; Hino, T.; Suzuki-Migishima, R.; Kohda, T.; Ogura, A.; et al. Role of retrotransposon-derived imprinted gene, Rtl1, in the feto-maternal interface of mouse placenta. Nat. Genet. 2008, 40, 243-248. [CrossRef]

47. Patten, M.M.; Cowley, M.; Oakey, R.J.; Feil, R. Regulatory links between imprinted genes: Evolutionary predictions and consequences. Proc. Biol. Sci. 2016, 283, 20152760. [CrossRef] 